\title{
Emergency Department Visits for Traumatic Brain Injury in a Birth Cohort of Medicaid-Insured Children
}

\author{
Charles DiMaggio, PhD, MPH \\ Guohua Li, MD, DrPH \\ Departments of Anesthesiology and Epidemiology \\ Columbia University \\ College of Physicians and Surgeons \\ New York, NY 10032
}

\begin{abstract}
Objectives: To analyze emergency department-based cohort data on pediatric traumatic brain injury (TBI.

Methods: We constructed a retrospective cohort of 493,890 children who were born in New York City between 1999 and 2007 and who were enrolled in the New York Medicaid program at the time of their birth, and followed these children from birth to the end of 2007.

Results: There were 62,089 injury-related emergency department visits of which 1,290 had ICD-9 codes consistent TBI. Children with TBI were more likely to be male $(59.4 \%$ vs. $51.4 \%$ ) and Hispanic (43.9\% vs. $26.3 \%$ ) than those in the underlying birth cohort, and were more than twice as likely to be admitted to the hospital for inpatient care ( $R R=2.4$ $95 \%$ CI 2.2, 2.6). The most commonly listed cause of injury was falls $(58.3 \%)$. Spatially-smoothed risk estimates indicated that Some areas of the city are associated with a greater risk of pediatric TBI than others.

Conclusions: Emergency department data can be used to describe pediatric TBI in ways not easily available through more routinely collected administrative health data. This information can be used to target prevention and control efforts.
\end{abstract}




\section{Introduction}

Traumatic brain injury (TBI) is the leading cause of death and disability in the United States from birth to age 19 and is present in up to $85 \%$ of all injured children. [1]. It is 'the most common cause of acquired disability in children' [2] and is of particular concern in the youngest children [3]. Children under the age of 5 are anatomically and physiologically more vulnerable to TBI than other age groups due to their greater headto-body-size ratio, thinner cranial bones and lower proportion of mylenated neural tissue. [4]

Beyond the immediate mortality and morbidity, the sequelae of pediatric TBI, particularly in the youngest age groups, are a source of continuing concern. These include epilepsy (with the risk approaching 50\% in children with direct parynchemal injuries), [5] 'persisting and comprehensive ... neuropsychological deficits in children with moderate ... brain injury' [6], and impairments to executive function [7]. Belief in the plasticity of the developing brain and its ability to rebound from most injury has been called 'unsubstantiated', and what might be considered even moderate or mild injury may result in 'cognitive, personality and adaptive dysfunction (that) plague victims into maturity'. [8]

While there has been an appreciable over-all decline in pediatric hospitalizations for TBI, that decline has been attributed to a relative decline in admissions for the mildest injuries. [9] Fatalities have remained essentially the same over that time period at 2 per 100,000 hospitalizations for the 0-4 age group, and 1 per 100,000 hospitalizations for the 5-9 age group. [9] Minority and lower socioeconomic groups continue to suffer disproportionately. [10]

Much of what we know about TBI is based on national and state-level data, and much of that on hospital discharge data. We know relatively little about TBI at the communitybased, ambulatory, and emergency department level. [11], where preventative and control efforts may be most effective. There have been, to our knowledge, no community-based cohort studies of emergency department visits for TBI in early childhood in a population of socially vulnerable children.

In this study, we examine emergency department and outpatient service records for children born between 1999 and 2007 and covered by New York Medicaid. We present the descriptive epidemiology of TBI in this population. By taking this outpatient, longitudinal population-based approach to describing the occurrence and location of injuries, we hope to inform potential preventative and control efforts.

\section{Methods}

We created a retrospective cohort of all children born into the New York State Medicaid system between 1999 and 2007 by examining Medicaid Analytic Extract (MAX) files. [12] These are a complete set of person-level data files on all New York State residents eligible for health care services under the state Medicaid program. 
The data files are compiled by the Centers for Medicare and Medicaid Services (CMS) from claim information provided by the New York State Department of Health. Health care providers submit standardized claims [13] that include clinical information that is most commonly abstracted from patient charts by non-clinician administrative personnel. CMS routinely conducts validation studies of MAX data and researchers have analyzed and validated the reliability of these data for studies of outpatient diagnoses in New York State. [14] These data have previously been described and used for epidemiological analyses. [15, 16, 17, 18]

We examined records for all outpatient services provided to Medicaid beneficiaries for the years 1999 to 2007, and for each year, selected only those records for individuals born between 1999 and 2007. We used place-of-service variables and provider specialty codes to restrict entries to those for emergency department services. After removing duplicate entries for the same health event in the same child, and restricting to children whose birth was covered by Medicaid, we applied the Barell Matrix [19] to the set of unique emergency department records for children born between 1999 and 2007 to identify first or primary ICD-9 diagnosis codes consistent with traumatic brain injury.

The Barell injury diagnosis matrix is a tool to standardize the classification of ICD-9 injury codes 800 to 995 according to 12 nature-of-injury columns and 36 body-location rows. $[19,20]$ Three sub-categories are available to classify TBI, with a single collapsed category of TBI based on a definition for the Centers for Disease Control and Prevention. [21]

In addition to ICD-9 diagnostic codes, each observation contained information on date of birth, gender, race, and ZIP Code of residence. We restricted our analyses to children with ZIP Codes of residence within New York City. We tabulated overall and annual incidence of emergency department services for TBI for all children, for children under the age of 1 , for children age 1 to 3 , and for children age 4 to 6 . We based our choice of these age groups on literature describing changing patterns of injury among young children. [22]

We abstracted demographic and descriptive statistics for all children born into New York City Medicaid between 1999 and 2007 who presented to emergency departments with TBI. We calculated yearly incidence rates separately for the 1999, 2000 and 2001 birth cohorts as well as gender-specific yearly incidence rates for those children less than 1 year old, 1 to 3 years old and 4 to six years old. Cause of injury was assessed using ecodes.

We calculated ZIP-Code population-based TBI incidence rates for all children born into New York City Medicaid between 1999 and 2001. We based these rates on population and gender adjusted standardized morbidity ratios (SMR) and spatially smoothed the rates using Bayesian hierarchical methods that incorporated a conditional autoregression (CAR) and random effect term. [23] Icite\{Lawson2009\}

Analyses and and graphing were conducted with the R statistical program. [24] 
The study was approved by the edited for blinded peer review institutional review board under protocol number edited for blinded peer review.

\section{Results}

There were a total of 493,890 children born into the New York City Medicaid system between 1999 and 2007, accounting for $45.9 \%$ of all live births reported by the New York State Department of Health. [25] These children received 62,089 injury-related emergency department diagnoses. From these diagnoses, we identified 1,290 children with non-duplicated emergency department ICD-9 diagnostic codes consistent with a Barell designation of traumatic brain injury (TBI).

While $8,852(14.3 \%)$ of the total 62,089 emergency department injury visits resulted in hospital admissions, 455 (35.3\%) of the 1,290 TBI children were admitted to the hospital, for a relative risk of admission of 2.4 (95\% CI 2.2,2.6). During the study period, 7 children died in the emergency department as a result of their injuries. Four of these deaths were due to TBI.

The most frequent diagnosis in the TBI group was ICD-9 code 850.00, "Concussion Without Coma" which accounted for 557 or $43 \%$ of the diagnoses. The next most frequent ICD-9 diagnoses were 854.00 ("Brain Injury NEC”) which accounted for 222 (17\%) of the TBI group and 850.90 ("Concussion NOS") which accounted for 89 (7\% of diagnoses).

The children in the TBI group were more likely to be male and Hispanic than those in the entire birth cohort. Of the 1,290 children in the TBI cohort, 766 (59.4\%) were male, compared to $51.4 \%$ male in the entire group of children in New York City Medicaid. Of the 934 TBI patients with a valid entry for race and ethnicity, $410(43.9 \%)$ were coded as Hispanic, compared to $26.3 \%$ Hispanic for the entire group of children with valid race/ethnicity entries. Emergency department diagnoses of TBI peaked during the summer months. (Figure 1)

Between 1999 and 2005, the overall incidence for emergency-department diagnosed TBI for the cohort was 29.2 / 10,000 person-years (33.1/10,000 person-years for males and $24.9 / 10,000$ person-years for females). The rates for males exceeded that for females at every age, and while the difference appeared particularly pronounced between 1 and 3 years old, it was only statistically significantly different for 6 and 7 year olds. (Table 1, Figure 2) The TBI incidence rates for children born in 1999, 2000 and 2001 did not differ in a way that suggested a cohort effect. Beyond age 5, it appeared that rates began to increase. (Figure 3)

Of the 173 emergency department TBI records with valid e-code entries, $101(58.3 \%)$ were coded as due to falls, with the next largest proportion of $59(34.1 \%)$ coded as due to "accident or other". Only 3 incidents $(1.7 \%)$ were coded as due to motor vehicle crashes. The remaining 10 cases $(5.7 \%)$ were coded as being due to "struck". These proportions did not differ appreciably when stratified by age group. (Figure 4) 
The risk of TBI varied spatially by age group across the city, (Figure 5), and some areas of New York City, particularly in Northern Manhattan and the Bronx had persistently increased risk relative to the city as a whole for the 4 age groups studied. Among children less than 3 years old, 5 of $132(3.7 \backslash \%)$ ZCTA's with data had relative risk estimates greater than 2 . This relative proportion increased with increasing age group. For 3 to 4 year olds, 6.7\\% (7/104) ZCTA's had more than twice the city-wide risk; for 5 to 6 year olds the proportion was $18.3 \backslash \%$ and for 7 to 8 year olds nearly half the city's ZCTA's $(461 \%)$ were at increased risk compared to the other half.

\section{Discussion and Limitations}

Pediatric traumatic brain injuries are an important emergency medicine, critical care and public health issue. Epidemiological analyses can help inform prevention, control and response by identifying who is a greatest risk, when the injuries are most likely to occur and the activities that put children at risk.

Our results are consistent with national data that show an increased risk for TBI among young children and among males. [26, 27], and we similarly demonstrate that the gender differential varies appreciably by age. The incidence of emergency department visits for TBI in this cohort was approximately 10 times that for hospital admissions for similarlyaged children in the United States [28].

Our results differ from a comprehensive and well-conducted recent study on emergency department visits for TBI which reported approximately twice the incidence than that found in this cohort. [29] This discrepancy can be explained in large part by differing definitions of TBI. The nationwide CDC report defined TBI using ICD9 diagnostic codes which include, importantly, code 959.01 ("Head Injury, Unspecified"). The Barell matrix, which we used, does not include that code. [19] We re-analyzed our data for all ages and all of New York State and found 49,348 such diagnoses, accounting for approximately 93\% of all TBI diagnoses in the state among Medicaid beneficiaries. We based our decision to use the Barell matrix on it's acceptance internationally, and as a way to identify severe cases of injury by body region using the most widely accepted ICD9 diagnostic codes.

We defined TBI based solely on the first or primary diagnostic code on the record. Other researchers have used any occurrence on any of multiple diagnostic fields, which may also contribute to discrepancies among reports. [29] We based our decision to restrict to the primary diagnosis as a way to increase the likelihood that the codes in fact reflected the diagnoses we thought they did, and on our observation that the secondary diagnostic fields frequently duplicated earlier diagnoses.

We would have liked to better describe the causes of injury. While falls were an important cause of TBI in this cohort, there are simply not enough data to draw any but the most cautious conclusions. Our primary conclusion about the E-code information in our data, is that E- codes are a potentially powerful feature of administrative health records whose usefulness is limited by their lack of utilization. 
Still, while E-code data could not offer more than the broadest indication of how risk was mediated in this group, the importance of falls as a mechanism of TBI in this population may reflect the risks posed by urban environments. While in most populations and environments the leading cause of TBI is motor vehicle crashes [30], in densely population urban areas such as New York City, falls take on greater importance. [31] This may account, in general, for the overall lower rate of unintentional injury-related pediatric mortality in New York City compared to the nation as a whole. [32], and in particular, the small proportion of cases attributable to motor-vehicle crashes (which include pedestrian injuries) in our study. Our results in this regard also likely reflect the decrease in pediatric pedestrian injuries in New York City over recent decades [33] due to such efforts such as Safe Routes to School [34]

Fall-related TBI in children has been linked to stairways [35]which are common in vertical cities like New York. Another important mechanisms of head injury due to falls in urban areas is window falls, which are more likely to occur in low-income neighborhoods, with children living in apartment buildings at 5 times the risk of those living in residences. [36] Notably, the "Children Can't Fly" project initiated in New York City in the 1970' s demonstrated that a program of education, engineering and enforcement could substantially reduce window-fall morbidity and mortality. [37]

Our results also indicate that mapping and spatial analytic techniques can help inform brain injury research. Some areas of the city are associated with a greater risk of pediatric TBI than others. This risk is likely due to variations in built environment, which has been linked to a number of health-related outcomes. Many injury and fall prevention strategies involve safety behavior and education such as avoiding baby walkers, using safety gates at the top and bottom of stairs, not leaving children unattended on changing tables, moving furniture and chairs away from windows, installing window safety guards and avoiding asphalt, concrete and soil surfaced playground. [38, 39] There are, though, areas for public health interventions that target built environment to prevent or control the consequences of fall-related TBI. For example, although $79 \%$ of playground injuries involve falls to the surface, $75 \%$ of public playgrounds lack adequate protective covering. [40,41] And while playground safety guidelines have been developed, and have been demonstrated to decrease medicallyattended injuries by $22 \%$ [42] only 15 states have enacted them. [43,44] Approaches to secondary prevention of the possible severe sequelae associated with TBI should take into account the reported improved outcomes for children treated in pediatric trauma centers. [1]

These analyses are subject to a number of important additional limitations based on the data source. Medicaid is a federal, state, and in New York State, a locally funded health insurance program with locally determined income, age, and disability requirements. This vulnerable group differs from the general population in ways that affect their health care utilization, [45]. Additionally, even under the best of circumstances, administrative data sets such as Medicaid MAX data, while informative, are blunt instruments with which to conduct epidemiological analyses. 


\section{Conclusions}

Given their ubiquity and clinical implications, TBI in children are critically important injuries and a continuing cause of public health concern. Emergency department data can be put to use to describe patterns of TBI by age, gender and cause. This descriptive study illustrates how the epidemiology of pediatric TBI differs by age group. Different behaviors as well as different exposure opportunities can be targeted for prevention and control efforts.

\section{References}

[1] Carli P and Orliaguet G. Severe traumatic brain injury in children. Lancet, 363(9409):584-585, 2004.

[2] Patterson C. M.. The role of the primary care physician in maximizing cognitive and behavioral recovery from moderate to severe pediatric traumatic brain injury. The Journal of the Arkansas Medical Society, 95(3):109-113, 1998.

[3] Bayreuther J., Wagener S. , Woodford M. , Edwards A. , Lecky F. , Bouamra O. , and Dykes E. . Paediatric trauma: injury pattern and mortality in the UK. Archives of Disease in Childhood. Education and Practice Edition, 94(2):37-41, 2009.

[4] Mazurek A. . Pediatric injury patterns. Int Anesthesiol Clin, 32(1):11-25, 1994.

[5] Lowenstein DH. Epilepsy after head injury: an overview. Epilepsia, 50 Suppl 2:4-9, 2009.

[6] Fay GC, K. Jaffe M, Polissar NL, Liao S, Rivara JB, and Martin KM. Outcome of pediatric traumatic brain injury at three years: a cohort study. Archives of Physical Medicine and Rehabilitation, 75(7):733-741, 1994.

[7] Levin HS and Hanten G. Executive functions after traumatic brain injury in children. Pediatric Neurology, 33(2):79-93, 2005.

[8] Parker RS. Neurobehavioral outcome of children's mild traumatic brain injury. Seminars in Neurology, 14(1):67-73, 1994.

[9] Bowman SM, Bird TM, Aitken ME, and Tilford JM. Trends in hospitalizations associated with pediatric traumatic brain injuries. Pediatrics, 122(5):988-993, 2008.

[10] Falcone RA, Martin C, Brown RL, and Garcia VF. Despite overall low pediatric head injury mortality, disparities exist between races. Journal of Pediatric Surgery, 43(10):1858-1864, 2008.

[11] Day H, Roesler J, Gaichas A, and Kinde M. Epidemiology of emergency department-treated traumatic brain injury in minnesota. Minnesota Medicine, 89(5):40-44, 2006.

[12] Centers for Medicare and Medicaid Services. Medicaid analytic extract (MAX) general information. 2006. [cited 11 October 2012] Available at http://www.medicaid.gov/Medicaid-CHIP-Program-Information/By-Topics/Dataand-Systems/MAX/MAX-General-Information.html 
[13] Ala A , Stanca CM , Bu-Ghanim M , Ahmado I , Branch AD , Schiano TD , Odin $\mathrm{JA}$, and Bach N . Increased prevalence of primary biliary cirrhosis near superfund toxic waste sites. Hepatology, 43(3):525-531, 2006.

[14] Walkup JT, Boyer CA, and Kellermann SL. Reliability of medicaid claims files for use in psychiatric diagnoses and service delivery. Adm Policy Ment Health, 27(3):129-139, 2000.

[15] DiMaggio C, Galea S, and Madrid P. SSRI prescription rates after a terrorist attack. Psychiatr Serv, 57(11):1656-1657, 2006.

[16] DiMaggio C, Galea S, and Richardson LD. Emergency department visits for behavioral and mental health care after a terrorist attack. Ann Emerg Med, 50(3):327-334, 2007.

[17] DiMaggio C, Galea S, and Emch M. Spatial proximity and the risk of psychopathology after a terrorist attack. Psychiatry Res, 176(1):55-61, 2010.

[18] DiMaggio C, Sun L, and Li G. Early childhood exposure to anesthesia and risk of developmental and behavioral disorders in a sibling birth cohort. Anesth Analg, 2011.

[19] Barell V, Aharonson-Daniel L, Fingerhut LA, Mackenzie EJ, Ziv A, Boyko V, Abargel A, Avitzour M, and Heruti R. An introduction to the Barell body region by nature of injury diagnosis matrix. Inj Prev, 8(2):91-96, 2002.

[20] Fingerhut LA, Aharonson-Daniel L, Mackenzie EJ, Ziv A, Boyko V, Abargel A, Avitzour M, and Heruti R. The barell matrix. Inj Prev, 8(3):259, 2002.

[21] Thurman. DJ., JE. Sniezek, and Johnson D. Guidelines for surveillance of central nervous system injury. Centers for Disease Control and Prevention, 1995.

[22] MacInnes K and Stone DH. Stages of development and injury: an epidemiological survey of young children presenting to an emergency department. BMC Public Health, 8:120, 2008.

[23] Lawson A. Bayesian disease mapping : hierarchical modeling in spatial epidemiology. Chapman \& Hall, Boca Raton, 2009.

[24] R Development Core Team. R: A language and environment for statistical computing. 2008(17 November), 2008.

[25] New York State Department of Health. Vital records.

[26] Faul M, Xu L, Wald MM, and Coronado VG. Traumatic brain injury in the united states: Emergency department visits, hospitalizations and deaths 2002 _ 2006. 2010.

[27] Sookplung P and Vavilala MS. What is new in pediatric traumatic brain injury? Curr Opin Anaesthesiol, 22(5):572-578, 2009.

[28] Incidence rates of hospitalization related to traumatic brain injury-12 states, 2002. MMWR Morb Mortal Wkly Rep, 55(8):201-204, 2006.

[29] CDC. Traumatic brain injury in the united states. 2011. 
[30] Colantonio A, Croxford R, Farooq S, Laporte A, and Coyte PC. Trends in hospitalization associated with traumatic brain injury in a publicly insured population, 1992-2002. The Journal of Trauma, 66(1):179-183, 2009.

[31] Barlow B, Niemirska M, Gandhi RP, and Leblanc W. Ten years of experience with falls from a height in children. J Pediatr Surg, 18(4):509-511, 1983.

[32] Thorpe LE. New york city child fatality report: 2009 report from the child fatality review team. 2009.

[33] DiMaggio C and Durkin M. Child pedestrian injury in an urban setting: descriptive epidemiology. Acad Emerg Med, 9(1):54-62, 2002.

[34] NYCDOT. Safety programs: Safe routes to schools. 2009, 2009.

[35] Boele van Hensbroek PB, Mulder S, Luitse JSK, van Ooijen MR, and Goslings JC. Staircase falls: high-risk groups and injury characteristics in 464 patients. Injury, 40(8):884-889, 2009.

[36] Stone KE, Lanphear BP, Pomerantz WJ, and Khoury J. Childhood injuries and deaths due to falls from windows. J Urban Health, 77(1):26-33, 2000.

[37] Spiegel CNand Lindaman FC. Children can't fly: a program to prevent childhood morbidity and mortality from window falls. 1977. Inj Prev, 1(3):194-198, 1995.

[38] Britton JW. Kids can't fly: preventing fall injuries in children. WMJ, 104(1):33$36,2005$.

[39] Vish NL, Powell EC, Wiltsek D, and Sheehan KM. Pediatric window falls: not just a problem for children in high rises. Inj Prev, 11(5):300-303, 2005.

[40] Tinsworth DK and McDonald JE. Special study: Injuries and deaths associated with children_s playground equipment. 2001.

[41] Weintraub R and Cassady A. Playing it safe: the sixth nationwide safety survey of public playgrounds. 2002 .

[42] Kotch JB, Hussey JM, and Carter A. Evaluation of north carolina child care safety regulations. Inj Prev, 9(3):220-225, 2003.

[43] National Safe Kids Campaign NSKC. Playground injury fact sheet. 2009, 2004.

[44] National Program for Playground Safety NPPS. National program for playground safety-standards, state regulations. 2009(November 2), 2006.

[45] Salsberry PJ, Chipps, E and Kennedy C. Use of general medical services among medicaid patients with severe and persistent mental illness. Psychiatr Serv, 56(4):458-462, 2005. 


\section{Tables and Figures}

Table 1: Age and Gender Stratified TBI Incidence Rates (95\%CI) per 10,000 person-years. New York City Medicaid Birth Cohort, 1999-2007

$\begin{array}{lll}\text { Age } & \text { Males } & \text { Females } \\ <1 & 7.7(3.9,11.4) & 9.7(5.4,14.1) \\ 1 & 23.8(17.1,30.5) & 17.5(11.5,23.4) \\ 2 & 33.3(24.9,41.6) & 21.7(14.8,28.6) \\ 3 & 42.9(34.2,51.6) & 31.1(23.5,38.7) \\ 4 & 17.1(12.3,22.0) & 15.9(11.1,20.7) \\ 5 & 15.7(11.2,20.1) & 13.4(9.2,17.5) \\ 6 & 46.9(39.4,54.5) & 31.3(24.9,37.6) \\ 7 & 38.7(32.8,44.5) & 32.1(26.3,37.8) \\ 8 & 52.3(45.5,59.1) & 37.4(31.3,43.6)\end{array}$

Figure 1: Monthly Proportion of Emergency Department TBI Diagnoses New York City Medicaid Birth Cohort 1999-2007 
Monthly Proportion of Emergency Department TBI Diagnoses New York City Medicaid Birth Cohort 1999-2007

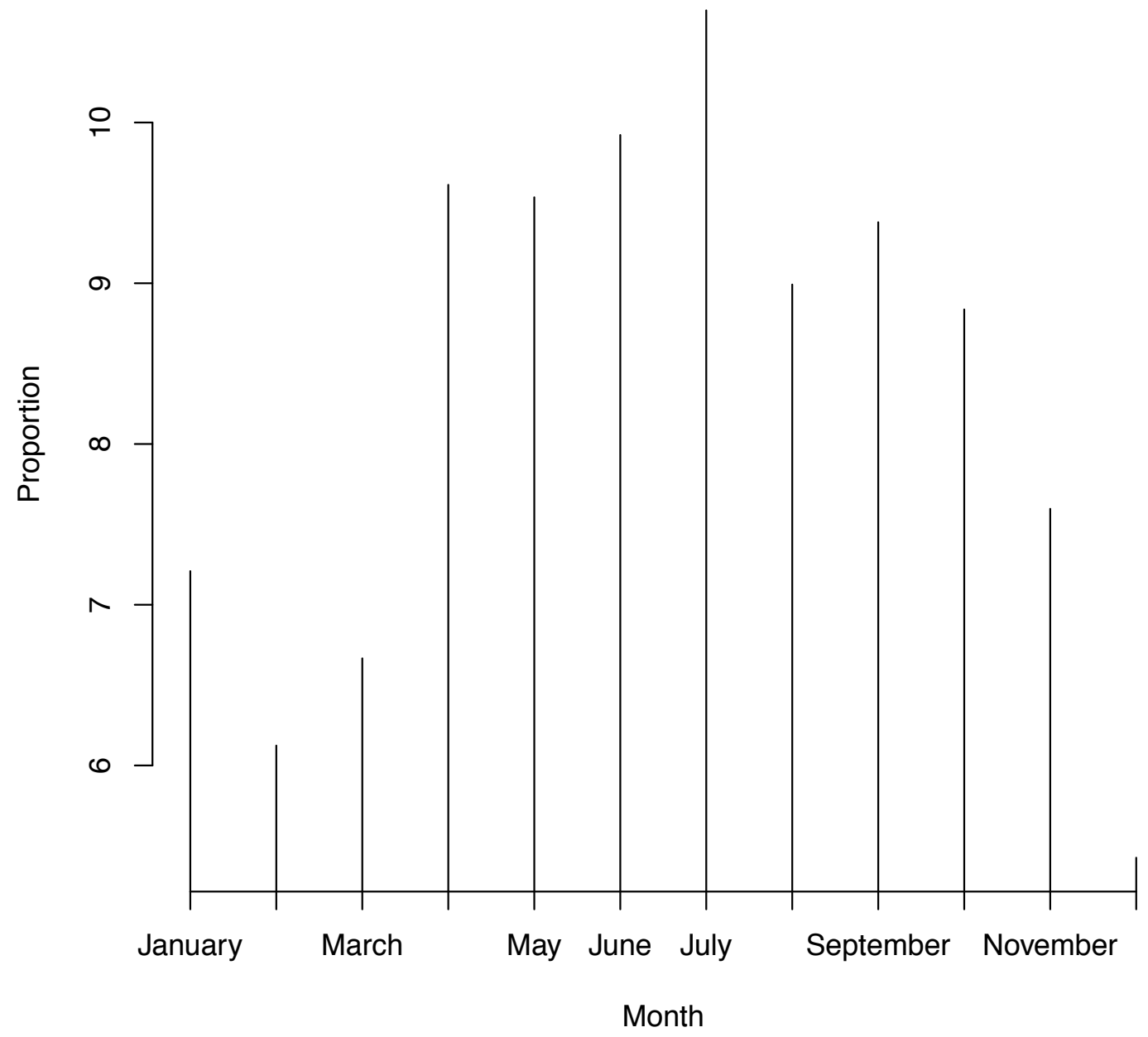

Figure 2: Age Stratified TBI Incidence Rate per 10,000 New York City Medicaid Birth Cohort 1999-2007 


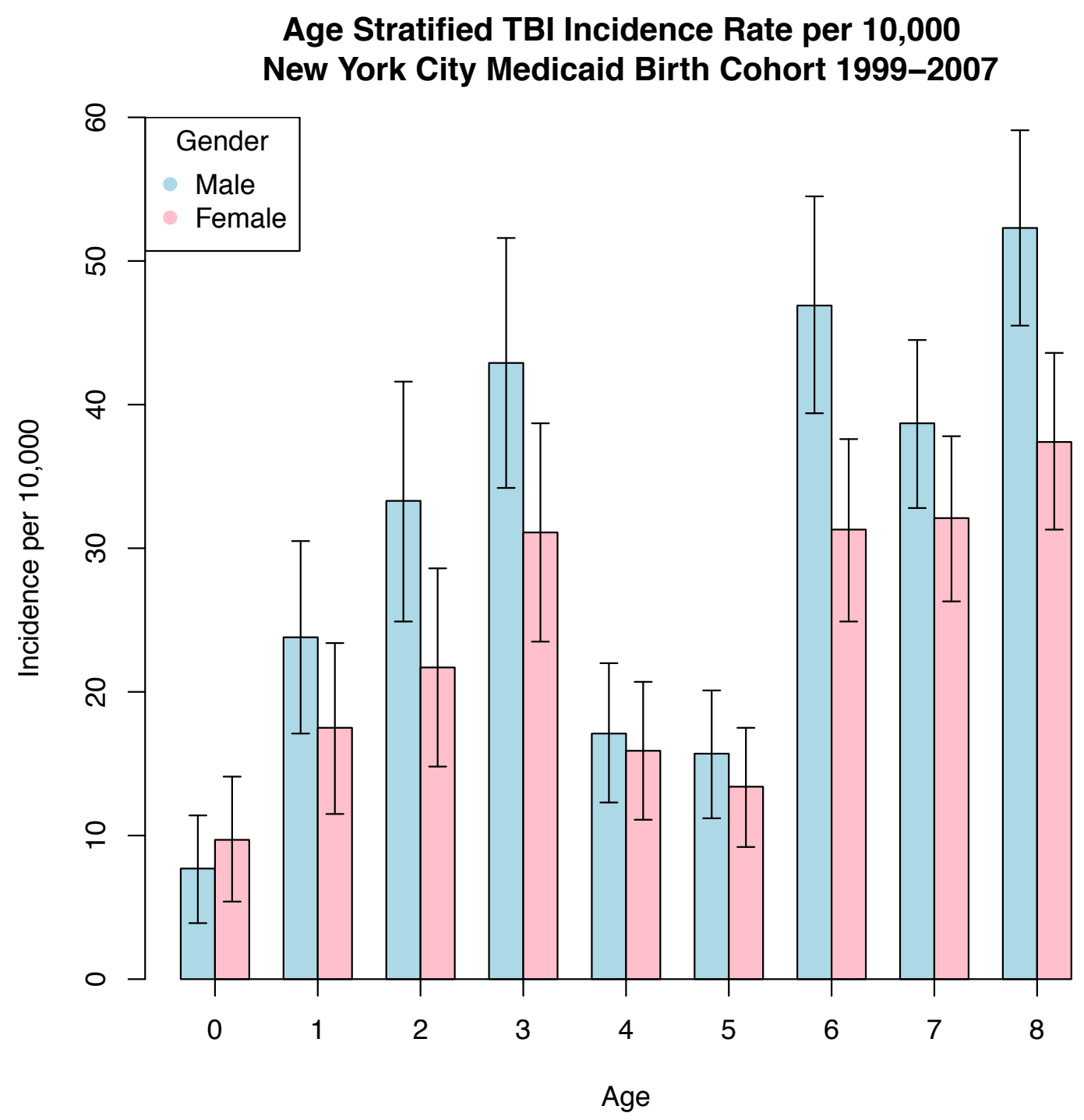

Figure 3: TBI Incidence Rate per 10,000 by Birth Cohort New York City Medicaid Data 


\section{TBI Incidence Rate per 10,000 by Birth Cohort New York City Medicaid Data}

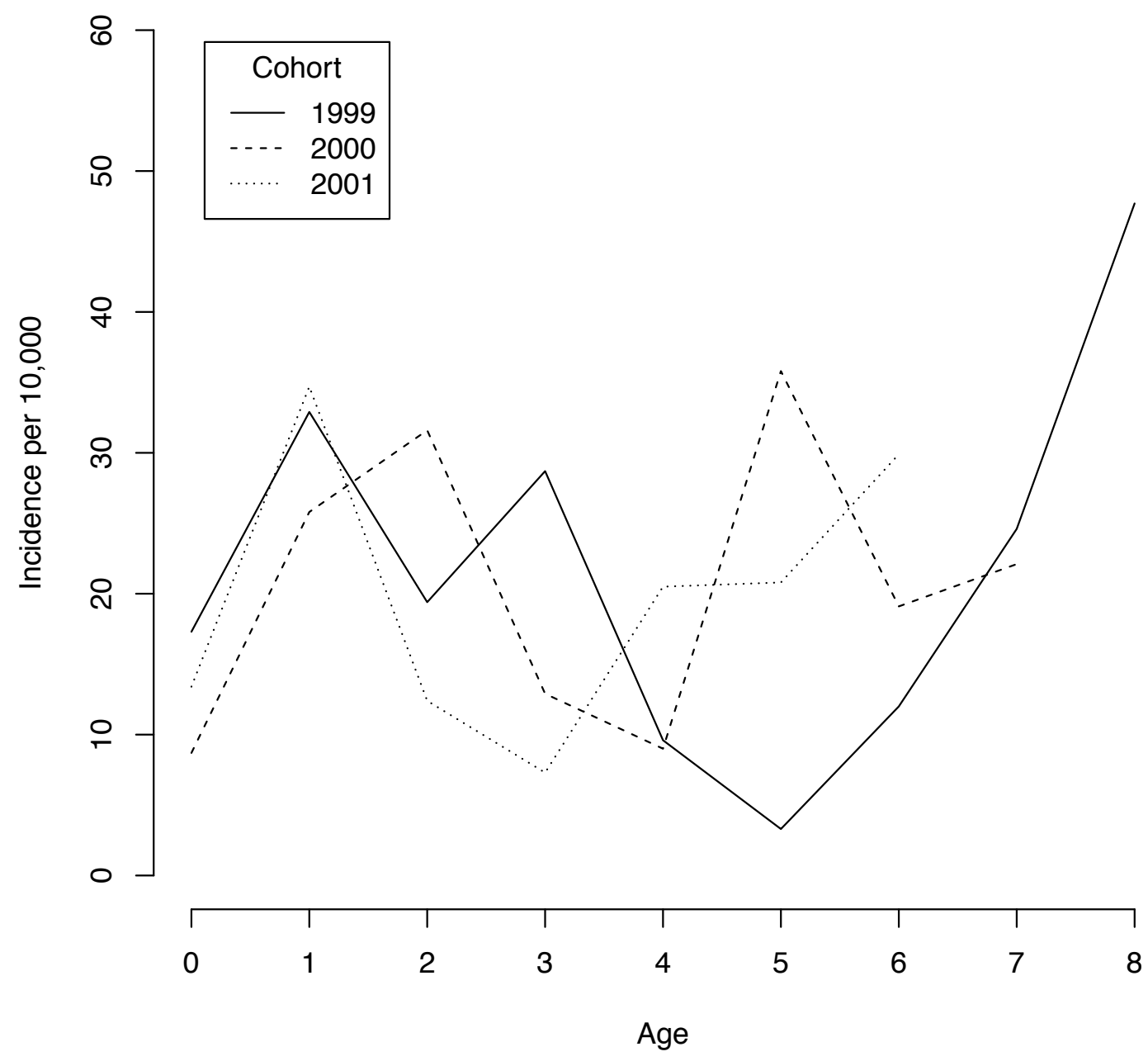

Figure 4: E-codes Emergency Department TBI Diagnoses, New York City Medicaid Birth Cohort, 1999-2007 


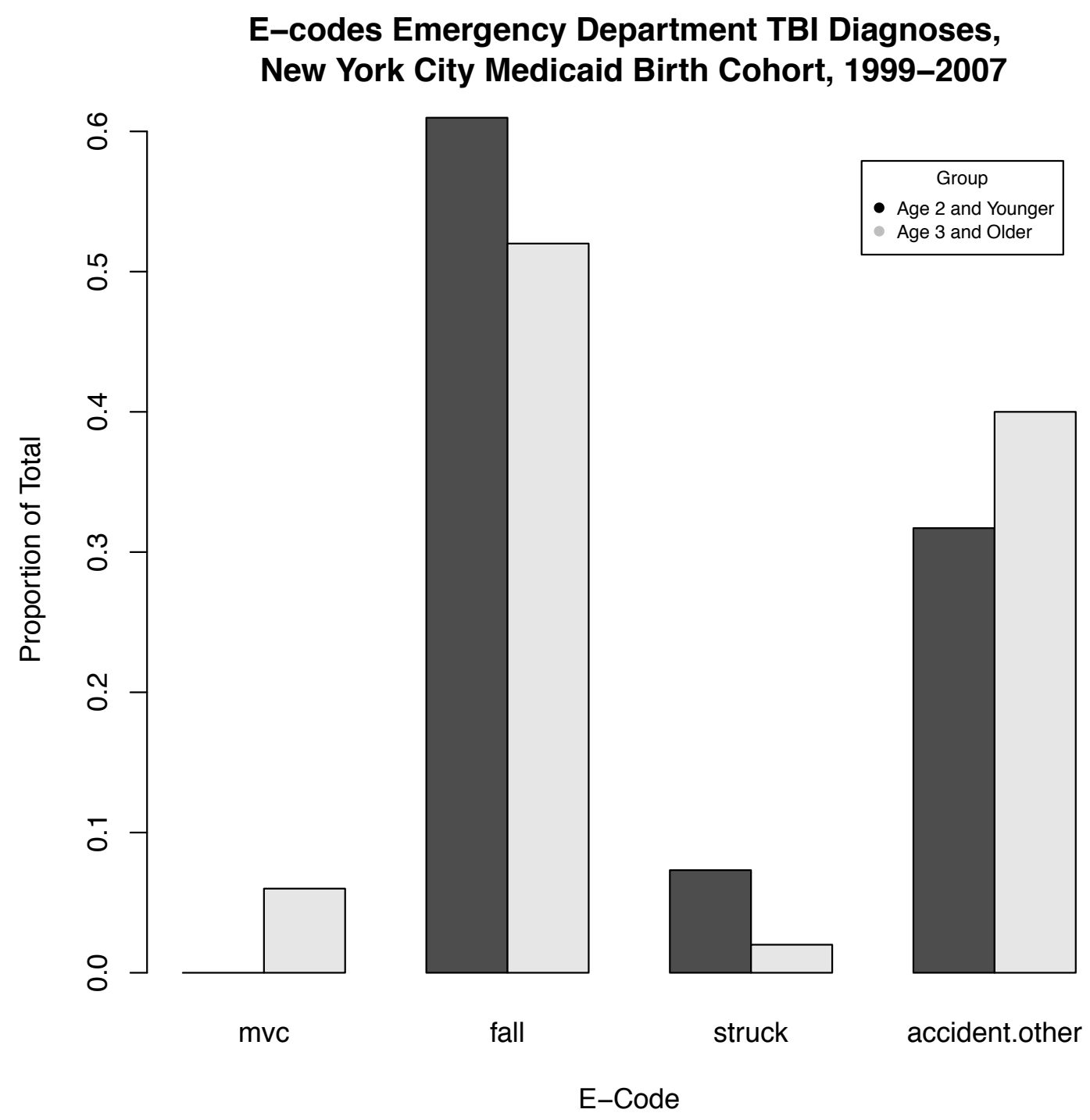

Figure 5: Gender-Standardized Bayesian-Smoothed TBI Relative Risk Estimates by Ageln and ZIP-Code Tabulation Area. NYC Medicaid Birth Cohort, 1999-2007 (Relative Risk Standardized to NYC) 


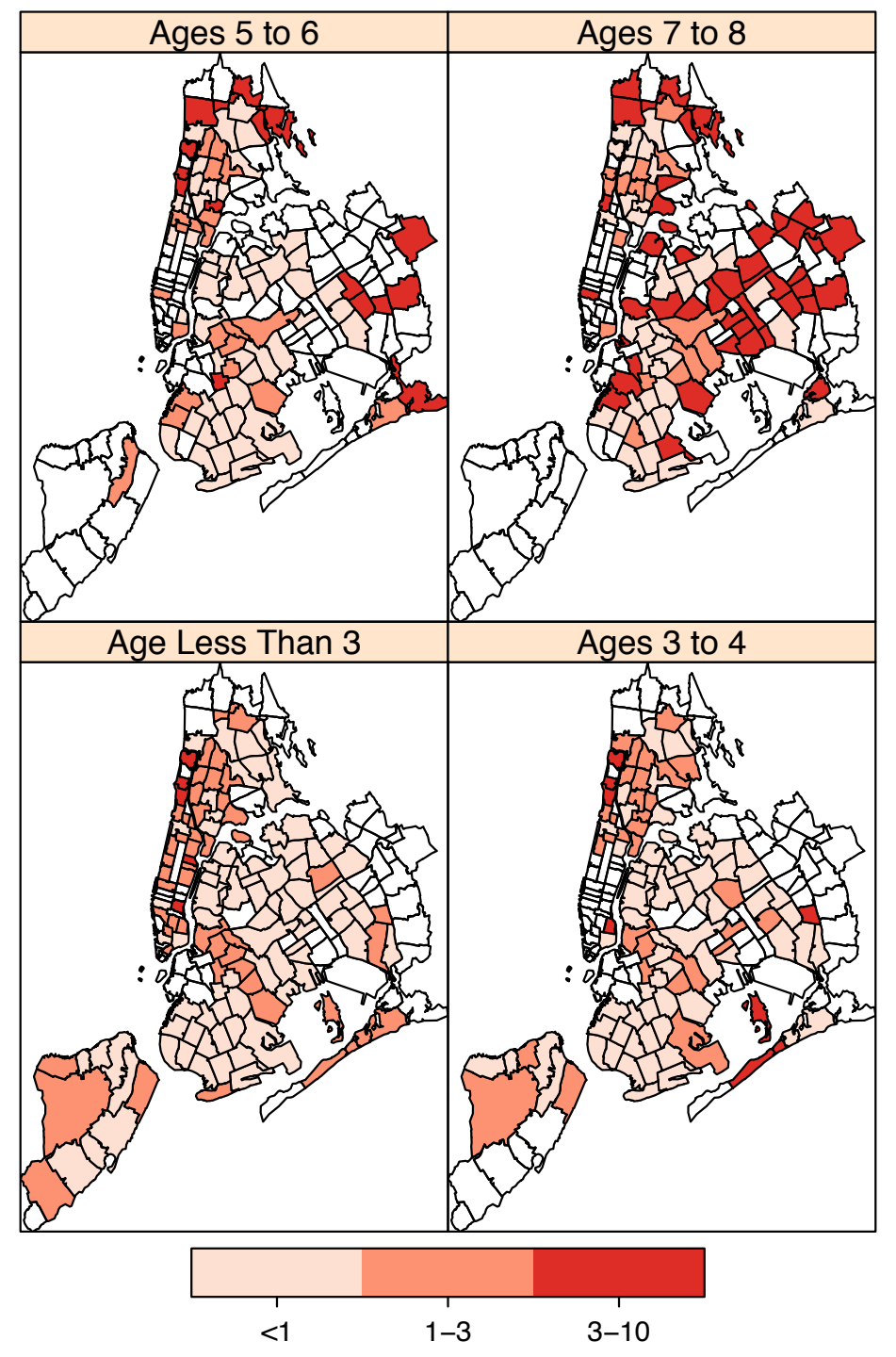

